\title{
Variation in Microsatellite Loci Reveals a Natural Boundary of Genetic Differentiation among Pyrus betulaefolia Populations in Northern China
}

\author{
Yu Zong ${ }^{1}$ \\ Department of Horticulture, Zhejiang University, Hangzhou, Zhejiang 310058, China; The Key \\ Laboratory of Horticultural Plant Growth, Development and Quality Improvement, The Ministry of \\ Agriculture of China, Hangzhou, Zhejiang 310058, China; Zhejiang Provincial Key Laboratory of \\ Integrative Biology of Horticultural Plants, Hangzhou, Zhejiang 310058, China; and College \\ of Chemistry and Life Sciences, Zhejiang Normal University, Jinhua, Zhejiang 321004, China \\ Ping Sun ${ }^{1}$ \\ Department of Horticulture, Zhejiang University, Hangzhou, Zhejiang 310058, China; The Key \\ Laboratory of Horticultural Plant Growth, Development and Quality Improvement, The Ministry of \\ Agriculture of China, Hangzhou, Zhejiang 310058, China; Zhejiang Provincial Key Laboratory of \\ Integrative Biology of Horticultural Plants, Hangzhou, Zhejiang 310058, China; and Jinhua Academy \\ of Agricultural Sciences, Jinhua, Zhejiang 321000, China

\begin{abstract}
Xiaoyan Yue, Qingfeng Niu, and Yuanwen Teng ${ }^{2}$
Department of Horticulture, Zhejiang University, Hangzhou, Zhejiang 310058, China; The Key Laboratory of Horticultural Plant Growth, Development and Quality Improvement, The Ministry of Agriculture of China, Hangzhou, Zhejiang 310058, China; and Zhejiang Provincial Key Laboratory of Integrative Biology of Horticultural Plants, Hangzhou, Zhejiang 310058, China
\end{abstract}

\begin{abstract}
AdDitional INDEX wORDs. genetic diversity, genetic structure, gene flow, phylogeography, conservation, SSR
Abstract. Pyrus betulaefolia is one of the most popular pear (Pyrus) rootstocks in China and other east Asian countries because of its good adaptability to versatile environments. However, the number of wild $P$. betulaefolia populations is decreasing because of habitat destruction and fragmentation. An urgent evaluation of $P$. betulaefolia genetic diversity and population structure is necessary to develop a conservation strategy for this important wild species. Thirteen simple sequence repeat loci were detected to infer the genetic composition of $18 P$. betulaefolia populations in northern China. The average number of different alleles for each locus was 7.1. The number of effective alleles among loci ranged from 1.77 to 5.94. The overall mean values of expected and observed heterozygosity were 0.702 and 0.687 , respectively. The Taihang Mountains, which run from northeast to southwest, acted as natural boundary in shaping the genetic diversity of $\boldsymbol{P}$. betulaefolia in northern China. The distinct pattern, which was also observed in the distribution of chloroplast DNA (cpDNA) variation, appeared to be obscured by pollen-mediated gene flow in the distribution of nuclear microsatellite variation. Large populations with high allelic richness (e.g., populations BT, ZN, and QS) are considered suitable for in situ conservation because of the potential for adaptation to future environmental change. The smaller populations had mixed gene pools (e.g., populations GQ and XF) and should therefore also be considered for ex situ conservation. Preserving genetic diversity in seeds was proposed when field collections are fully characterized.
\end{abstract}

The magnitude of genetic variability within species is a fundamental source of biodiversity (Hughes et al., 2008) because intraspecific genetic diversity can enhance the evolutionary trajectory of a species by increasing heterozygosity and demographic equilibrium (Jump et al., 2009). Wild species generally contain more genetic variability than cultivated species (Klepo et al., 2013). This naturally occurring variation in wild species is an underexploited resource for plant breeding

Received for publication 6 Feb. 2017. Accepted for publication 7 June 2017. This work was supported by the National Natural Science Foundation of China (No. 30871690), Major Program for Science and Technology of Zhejiang Province of China (No. 2016C02052-4), and the Advanced Technology Innovation Team for Horticultural Crop Breeding of Zhejiang Province of China (2013TD05).

${ }^{1}$ These authors contributed equally to this work.

${ }^{2}$ Corresponding author. E-mail: ywteng@zju.edu.cn. as a narrow genetic base can render cultivated species vulnerable to disease and insect attack (Zamir, 2001). Consequently, wild germplasm has been treated as a valuable and informative reservoir of beneficial traits for genetic improvement of cultivated species (Fernie et al., 2006).

However, some wild species are endangered or near extinct because of rapid environmental change and ongoing habitat fragmentation (Ge et al., 2005; Jump et al., 2009; Liu et al., 2013; Richards et al., 2009). This led to an urgent call to preserve wild germplasm (Heywood et al., 2007; Meilleur and Hodgkin, 2004). When attempting to develop an efficient strategy for conservation, an assessment of genetic diversity in wild populations of species is therefore imperative for better management (Atangana et al., 2010; Boccacci et al., 2013).

Pyrus betulaefolia, as the most popular pear rootstock in China and other east Asian countries for its good adaptability to 
versatile environments (Okubo and Sakuratani, 2000; Robbani et al., 2006; Tamura, 2012), is mainly distributed in northern China, including Henan, Hebei, Shandong, Shanxi, Shaanxi, and Gansu provinces (Yu, 1979). Pyrus betulaefolia is the only species whose fruit lack flavone glycosides in all species of Pyrus in Asia (Challice and Westwood, 1973) and is the sole oriental pear species showing monophyletic in molecular phylogenetic tree (Zheng et al., 2011, 2014); therefore, this species would play an important role in the evolution of the genus Pyrus. However, the number of wild P. betulaefolia populations is decreasing because of habitat destruction and fragmentation (Zong et al., 2013). It is urgent to evaluate the genetic diversity and population structure of $P$. betulaefolia for development of a conservation strategy for this wild species.

Until now, the genetic diversity of a few Pyrus species has been evaluated by noncoding regions of cpDNA; Liu et al. (2013) and Wuyun et al. $(2013,2015)$ used different cpDNA fragments to evaluate the genetic diversity of $P$. pashia and $P$. ussuriensis, respectively. Our previous study using cpDNA showed that $P$. betulaefolia populations in northern China contained a high level of genetic diversity and experienced rapid range expansion (Zong et al., 2014), and both restricted gene flow with isolation by distance (IBD) and allopatric fragmentation were crucial processes responsible for shaping the genetic patterns of $P$. betulaefolia. Although the genetic diversity studies based on noncoding regions of cpDNA provide some theoretical references for $P$. betulaefolia conservation, cpDNA only reflects the maternal lineage (Birky, 1995) and is considered a single unit of inheritance because it is not subject to recombination (Schaal et al., 1998). These features can lead to relatively high population differentiation because of the lower dispersal potential in seeds than pollen, greater genetic drift of the haploid genome in small refugial populations, or both (Newton et al., 1999). Simple sequence repeats (SSRs) in nuclear genome, which are randomly distributed across eukaryotic genomes, have been widely used to detect genetic differentiation within species because of their high polymorphism levels and codominant inheritance
(Asuka et al., 2004; Godoy and Jordano, 2001). Compared with cpDNA markers, the contrasting patterns of SSR inheritance could be used to elucidate the complexity of gene flow in plants because they are predicted to result in different distributions of genetic diversity within and among populations (Birky et al., 1989). In addition, it is possible to examine phylogeographical events that occurred by seed and pollen movement. Using SSR markers, some studies have focused on assessing the genetic diversity of Pyrus germplasm including wild species and cultivars (Ahmed et al., 2010; Liu et al., 2015; Miranda et al., 2010; Rana et al., 2015; Wolko et al., 2015) to guide their efficient use and conservation. However, the genetic diversity and population structure of $P$. betulaefolia, one of the most important wild Pyrus species, are not yet understood. Therefore, estimation of $P$. betulaefolia genetic and phylogeographic structures based on SSR analysis is needed.

In this study, we analyzed the geographical distribution of polymorphisms in nuclear microsatellite loci from the $18 P$. betulaefolia populations that were reported in our previous study (Zong et al., 2014). The main purpose of this study was to 1) evaluate the genetic differentiation within and among $P$. betulaefolia populations and 2) detect whether the pattern and level of genetic diversity are associated with geographic distribution of $P$. betulaefolia, which will assist in the development of a conservation strategy for P. betulaefolia.

\section{Materials and Methods}

Plant materials. The sampling procedure and samples used in this study were the same as those reported in our previous study (Zong et al., 2014). Briefly, young healthy leaves were sampled from 326 individuals of 18 natural $P$. betulaefolia populations in northern China (Table 1). The distance between adjacent sampling trees within a population was at least $20 \mathrm{~m}$ to avoid sampling clones. Detailed geographic information of samples is shown in Table 1 of Zong et al.

Table 1. Pyrus betulaefolia populations surveyed in northern China and their sample size, location and geographical parameters.

\begin{tabular}{|c|c|c|c|c|c|c|c|}
\hline $\begin{array}{l}\text { Population } \\
\text { code }\end{array}$ & $\begin{array}{c}\text { Individuals } \\
\text { (no.) }\end{array}$ & Collection location & $\begin{array}{l}\text { Latitude } \\
\left({ }^{\circ} \mathrm{N}\right)\end{array}$ & $\begin{array}{c}\text { Longitude } \\
\left({ }^{\circ} \mathrm{E}\right)\end{array}$ & $\begin{array}{l}\text { Altitude } \\
(\mathrm{m})\end{array}$ & $\begin{array}{c}\text { Annual } \\
\text { rainfall } \\
(\mathrm{mm})^{z}\end{array}$ & $\begin{array}{c}\text { Annual } \\
\text { avg temp } \\
\left({ }^{\circ} \mathrm{C}\right)^{\mathrm{z}}\end{array}$ \\
\hline$\overline{\mathrm{BT}}$ & 21 & Baota District, Yan'an City, Shaanxi Province & 36.49 & $109.60-109.61$ & $1287-1348$ & 480.8 & 10.4 \\
\hline FX & 16 & Fuxian County, Shaanxi Province & $36.08-36.09$ & 109.50 & $1102-1148$ & 532.8 & 9.5 \\
\hline GQ & 16 & Ganquan County, Shaanxi Province & $36.27-36.28$ & $109.36-109.38$ & $1130-1197$ & 530.5 & 9.2 \\
\hline $\mathrm{HC}$ & 23 & Huachi County, Gansu Province & $36.36-36.37$ & $108.19-108.21$ & $1427-1545$ & 470.6 & 8.7 \\
\hline $\mathrm{ZN}$ & 20 & Zhengning County, Gansu Province & 35.34 & 108.21 & $1278-1299$ & 609.7 & 9.2 \\
\hline NX & 21 & Ningxian County, Gansu Province & $35.45-35.48$ & $107.90-107.95$ & $950-1165$ & 564.1 & 9.0 \\
\hline $\mathrm{CL}$ & 12 & Changli County, Hebei Province & $39.73-39.74$ & $119.14-119.16$ & $47-181$ & 602.9 & 11.7 \\
\hline LB & 16 & Lingbao County, Henan Province & 34.41 & 111.10 & $841-916$ & 600.5 & 13.5 \\
\hline LS & 15 & Lushi County, Henan Province & 34.37 & $111.06-111.07$ & $714-1024$ & 568.7 & 13.9 \\
\hline NQ & 22 & Neiqiu County, Hebei Province & $37.34-37.35$ & $114.19-114.21$ & $341-400$ & 502.6 & 12.8 \\
\hline SX & 21 & Shexian County, Hebei Province & 36.51 & $113.57-113.58$ & $628-703$ & 535 & 12.8 \\
\hline WG & 20 & Wugang County, Henan Province & 33.31 & $113.47-113.49$ & $164-234$ & 957.6 & 15.1 \\
\hline
\end{tabular}

${ }^{\mathrm{z}}$ Average value from 1981 to 2010 (China Meteorological Data Service Center, 2012). 
(2014). The leaves were dried in silica gel. The sampling areas covered most of the geographic distribution area of $P$. betulaefolia that was previously investigated $(\mathrm{Pu}$ and Wang, 1963; Zong et al., 2013). The position of each sampled tree was determined using a portable global positioning system (Triton 500; Magellan, Santa Clara, CA).

DNA Extraction. Genomic DNA was extracted from the silica gel-dried leaf tissue following the modified hexadecyl trimethyl ammonium bromide protocol described by Doyle and Doyle (1987). DNA was dissolved in the Tris-HCl and EDTA buffer $(\mathrm{pH}=8.0)$, and the DNA concentration was diluted to $10-30 \mathrm{ng} \cdot \mu \mathrm{L}^{-1}$ after accessing the quality and quantity on $1 \%$ (w/v) agarose gels using standard DNA markers (TaKaRa, Dalian, China).

Polymerase chain Reaction (PCR) amplification AND SSR ANALYSES. Sixteen previously developed polymorphic SSR primer pairs, including five apple (Malus $\times$ domestica) microsatellite primers (Gianfranceschi et al., 1998; Guilford et al., 1997; Liebhard et al., 2002), six pear microsatellite primers (Yamamoto et al., 2002a, 2002b), and five apple expressed sequence tag-derived SSR primers (Yao et al., 2010) were used to carry out PCR. Amplifications were performed in a thermal cycler (Mastercycler Gradient; Eppendorf, Hamburg, Germany) in a total volume of $15 \mu \mathrm{L}$, which included $10 \mathrm{ng}$ DNA template, $0.4 \mu \mathrm{M}$ of each primer, $200 \mu \mathrm{M} \mathrm{dNTPs}, 2 \mathrm{mM} \mathrm{MgCl}_{2}$, and $0.5 \mathrm{U}$ Taq DNA polymerase (TaKaRa). Primers KA4b, KA14, BGT23, and $28 \mathrm{f} 4$ were amplified under the following conditions: initial denaturation at $94{ }^{\circ} \mathrm{C}$ for $2 \mathrm{~min}$; 10 cycles of $94^{\circ} \mathrm{C}$ for $1 \mathrm{~min}, 60^{\circ} \mathrm{C}$ for $1 \mathrm{~min}$, and $72^{\circ} \mathrm{C}$ for $2 \mathrm{~min}$ (with the annealing temperature reduced by $0.5^{\circ} \mathrm{C}$ per cycle); and 25 cycles of $94^{\circ} \mathrm{C}$ for $1 \mathrm{~min}, 55^{\circ} \mathrm{C}$ for $1 \mathrm{~min}$, and $72^{\circ} \mathrm{C}$ for $2 \mathrm{~min}$. The cycling conditions for $\mathrm{CH} 01 \mathrm{~B} 12$ and $\mathrm{CH} 01 \mathrm{H} 01$ primers were $94{ }^{\circ} \mathrm{C}$ for $2 \mathrm{~min} 30 \mathrm{~s}$; four cycles of $94{ }^{\circ} \mathrm{C}$ for $30 \mathrm{~s}, 65^{\circ} \mathrm{C}$ for $1 \mathrm{~min}, 72{ }^{\circ} \mathrm{C}$ for $1 \mathrm{~min}$ (with the annealing temperature reduced by $1{ }^{\circ} \mathrm{C}$ per cycle); 30 cycles of $94{ }^{\circ} \mathrm{C}$ for $30 \mathrm{~s}, 65^{\circ} \mathrm{C}$ for $1 \mathrm{~min}$, and $72^{\circ} \mathrm{C}$ for $1 \mathrm{~min}$. A final extension at $72{ }^{\circ} \mathrm{C}$ for $5 \mathrm{~min}$ was used for all of the described primers. PCRs for the other primers were performed as follows: $94{ }^{\circ} \mathrm{C}$ for $5 \mathrm{~min} ; 35$ cycles at $94{ }^{\circ} \mathrm{C}$ for $40 \mathrm{~s}, 55^{\circ} \mathrm{C}$ for $40 \mathrm{~s}$, and $72{ }^{\circ} \mathrm{C}$ for $40 \mathrm{~s}$; followed by extension at $72^{\circ} \mathrm{C}$ for $6 \mathrm{~min}$.

The PCR products were pooled together with the internal size standard (GeneScan 500 LIZ; Applied Biosystems, Foster City, CA) according to different dyes and expected fragment sizes and subsequently separated and sequenced using a genetic analyzer (ABI 3700XL; Applied Biosystems). Fragment sizes were assessed using GeneMapper 4.0 (Applied Biosystems).

Characteristics OF SSR PRIMERS AND Genetic DIVERSITY WITHIN $\boldsymbol{P}$. BETULAEFOLIa POPUlations. Allele size determination was manually performed twice to reduce errors, and null alleles were checked using MICRO-CHECKER (van Oosterhout et al., 2004). Linkage disequilibrium was tested for all locus pairs in each population by randomization using GENEPOP 4.0 (Raymond and Rousset, 1995; Rousset, 2008). For each locus and population, genetic diversity was estimated by calculating the number of different alleles $\left(N_{\mathrm{a}}\right)$, number of effective alleles $\left(N_{\mathrm{e}}\right)$, observed heterozygosity $\left(H_{\mathrm{o}}\right)$, expected heterozygosity $\left(H_{\mathrm{e}}\right)$, and Shannon's information index $(I)$ using GenAlEx 6.501 (Peakall and Smouse, 2006). The significance of deviation from Hardy-Weinberg equilibrium, which was inferred based on deviations of the fixation index $\left(F_{\text {is }}\right)$ from zero for each locus, was also estimated in GenAlEx 6.501. A sampleadjusted metric of allelic richness $\left(A_{\mathrm{r}}\right)$ was calculated using
FSTAT 2.9.3 (Goudet, 1995). Allele richness was standardized for 11 individuals.

Genetic DifFERENTIATION AMONG POPUlations. The number of homogeneous gene pools $(K)$ was evaluated using a Bayesian clustering approach executed in STRUCTURE 2.3.4 (Pritchard et al., 2000). This approach revealed genetic structure by assigning individuals or predefined groups to $K$ clusters. For the current study, we chose the admixture model without using population or other information as priors. Both correlated and independent allele frequencies were adopted during the modeling process. Different $K$ values that ranged from 1 to 15 were used to infer the number of clusters for 10 replicate runs. Each run was conducted for 200,000 Markov chain Monte Carlo iterations, with an initial burn-in of 100,000. Two approaches, one which used Delta $K$ values, where Delta $K=$ mean $\left(\left|L^{\prime \prime}(K)\right|\right) / s[L(K)]$ (Evanno et al., 2005), and one which used plateaued LnPr $(X \mid K)$ values, were performed to evaluate the most appropriate gene pool number ( $K$ value). The Delta $K$ method was conducted by uploading the STRUCTURE results to the STRUCTURE HARVESTER website (Earl and vonHoldt, 2012).

Replicate cluster analyses of the same data could produce different outcomes for estimated assignment coefficients, even though the same starting conditions were used (Jakobsson and Rosenberg, 2007). Therefore, CLUMPP version 1.1.2 (Jakobsson and Rosenberg, 2007) was employed to average the 10 independent simulations, and DISTRUCT version 1.1 (Rosenberg, 2004) was used to visualize the results. Maps with exact altitude and hydrologic data were drawn in DIVA-GIS 7.5.0 (Hijmans et al., 2001). Pie charts scattered on maps were plotted based on the obtained membership coefficients of individuals and populations with Adobe Illustrator CC 2015 (Adobe System, San Jose, CA). A neighbor-joining (NJ) tree for the 18 populations was constructed using Populations 1.2.31 (Langella, 2000) based on Nei's genetic distance, $D_{\mathrm{A}}$ (Nei et al., 1983). A previous study showed that phylogenetic trees constructed with the distance measure $D_{\mathrm{A}}$ could produce reliable results when analyzing microsatellite data (Takezaki and Nei, 2008). Trees were then presented and modified using DENDROSCOPE 3 (Huson and Scornavacca, 2012).

GENETIC DIVERSITY AND STRUCTURE OF POPULATION GROUPS. $A_{\mathrm{r}}, H_{\mathrm{o}}$, gene diversity $\left(H_{\mathrm{s}}\right)$, genetic differentiation among populations $\left(F_{\mathrm{st}}\right)$, and $F_{\text {is }}$ were calculated to assess the differences among population groups, then the differences among these parameters were evaluated based on 10,000 permutations with FSTAT 2.9.3 (Goudet, 1995). To test the significance of IBD, we performed a Mantel test with 10,000 permutations on matrices of pairwise $\Phi_{\mathrm{PT}}$ and $\log (1+$ geographic distance $)$ using GenAlEx 6.501 (Peakall and Smouse, 2006). These correlations were tested for all populations and populations within each group.

PyRUS BETULAEFOLIA GENE FLOW AMONG POPULATION GROUPS. To assess the extent and pattern of migration among population groups, we used the maximum likelihood-based and coalescent theory-based program MIGRATE 3.4.2 (Beerli and Felsenstein, 1999). MIGRATE has several advantages over estimates of migration, including providing realistic patterns of migration and explicitly simulating the mutation process (Beerli, 2007). Consequently, MIGRATE produces a robust estimation based on the stepwise mutation model that is suitable for the microsatellite markers that were used in our study (Beerli, 2007) and is less prone to sampling error in small population samples 
(Beerli and Felsenstein, 1999). This program calculates the posterior probability of the mutation-scaled effective size $(\Theta)$ and the mutation-scaled migration rate $(M)$. With these two parameters, gene flow $\left(x N_{\mathrm{m}}\right)$ can be estimated in terms of $x N_{\mathrm{m}}=\Theta_{\mathrm{i}} M_{\mathrm{i}} . x$ is a multiplier that depends on the ploidy and inheritance of the data; for nuclear data, $x=4$. We relied on maximum-likelihood estimation and used 10 short chains (10,000 trees) and three long chains $(1,000,000$ trees), with 10,000 trees discarded as the initial burn-in. Other parameters in the MIGRATE were set to the default values.

\section{Results}

CharaCteristics AND POLYMorphisms of SSRs. The linkage disequilibrium test indicated that three loci showed significant $(P<0.001)$ linkage disequilibrium with other loci. Therefore, these three loci were excluded from further analyses. Polymorphisms varied remarkably among remaining 13 SSR loci. The number of different alleles for each locus ranged from 3.4 (CH01B12) to 10.4 (MES122), with an average of 7.1 . The number of effective alleles among loci was 4.1 , with a range of 1.77-5.94. Shannon's information index for each locus ranged from 0.76 to 1.96 , with a mean value of 1.49 . The overall mean values of expected and observed heterozygosity were 0.702 and 0.687 , respectively. The $F_{\text {is }}$ for 13 loci ranged from -0.130 (MES96) to 0.168 (MES122). $F_{\text {is }}$ showed significant $(P<$ 0.001 ) deviation from zero at all loci except CH01B12 (Table 2).

Genetic diversity in $\boldsymbol{P}$. Betulaefolia populations. Genetic diversity varied dramatically among populations (Table 3 ). The allele number per population ranged from 4.6 (population $\mathrm{CY}$ ) to 8.2 (population $\mathrm{XF}$ ). $N_{\mathrm{e}}$ per population ranged from 2.2 (population CY) to 4.9 (population XF). Allelic richness varied from 3.89 to 7.62 among populations. Both observed and

Table 2. List of SSR markers used in the current study with number of alleles $\left(N_{\mathrm{a}}\right)$, number of effective alleles $\left(N_{\mathrm{e}}\right)$, Shannon's information index $(I)$, observed heterozygosity $\left(H_{\mathrm{o}}\right)$, expected heterozygosity $\left(H_{\mathrm{e}}\right)$, and fixation index $\left(F_{\mathrm{is}}\right)$.

\begin{tabular}{lrccccc}
\hline Locus & $N_{\mathrm{a}}$ & $N_{\mathrm{e}}$ & $I$ & $H_{\mathrm{o}}$ & $H_{\mathrm{e}}$ & \multicolumn{1}{c}{$F_{\text {is }}$} \\
\hline CH01B12 $^{\mathrm{z}}$ & 3.4 & 2.20 & 0.89 & 0.51 & 0.53 & 0.006 \\
CH01H01 $^{\mathrm{z}}$ & 7.3 & 4.65 & 1.66 & 0.74 & 0.78 & 0.028 \\
BGT23 $^{\mathrm{y}}$ & 5.9 & 3.09 & 1.34 & 0.73 & 0.68 & -0.104 \\
KA46 $^{\mathrm{y}}$ & 4.6 & 2.29 & 0.93 & 0.50 & 0.49 & -0.053 \\
KA14 $^{\mathrm{y}}$ & 9.1 & 5.27 & 1.83 & 0.81 & 0.81 & -0.032 \\
MES2 $^{\mathrm{x}}$ & 8.1 & 5.47 & 1.80 & 0.88 & 0.82 & -0.104 \\
MES7 $^{\mathrm{x}}$ & 9.3 & 5.68 & 1.90 & 0.83 & 0.83 & -0.029 \\
MES96 $^{\mathrm{x}}$ & 8.9 & 5.52 & 1.86 & 0.91 & 0.83 & -0.130 \\
MES122 $^{\mathrm{x}}$ & 10.4 & 5.94 & 1.96 & 0.67 & 0.83 & 0.168 \\
MES138 $^{\mathrm{x}}$ & 7.3 & 4.28 & 1.59 & 0.74 & 0.74 & -0.024 \\
NB109 $^{\mathrm{w}}$ & 4.3 & 1.77 & 0.76 & 0.38 & 0.39 & -0.001 \\
NH019 $^{\mathrm{w}}$ & 7.2 & 4.38 & 1.64 & 0.68 & 0.78 & 0.101 \\
28f4 & 5.8 & 2.81 & 1.24 & 0.56 & 0.62 & 0.084 \\
Mean & 7.1 & 4.10 & 1.49 & 0.69 & 0.70 & 0.009 \\
\hline SSR & & & & & &
\end{tabular}

$\mathrm{SSR}=$ simple sequence repeat.

${ }^{\mathrm{z}}$ SSR primers developed by Gianfranceschi et al. (1998) and tested in apple by Liebhard et al. (2002).

${ }^{\mathrm{y}} \mathrm{SSR}$ primers developed by Yamamoto et al. (2002a).

${ }^{\mathrm{x}} \mathrm{SSR}$ primers developed by Yao et al. (2010).

${ }^{\mathrm{w}}$ SSR primers developed by Yamamoto et al. (2002b).

${ }^{\mathrm{v}} \mathrm{SSR}$ primers developed by Guilford et al. (1997). expected heterozygosity slightly differed among populations, but the lowest expected heterozygosity $(0.51)$ appeared in population CY. Allelic richness in different populations showed substantial variation, with highest value in population XF (6.92) and lowest in population CY (3.89). Taking all of the genetic diversity indexes into consideration, populations $\mathrm{BT}$, GQ, NX, XF, ZN, LB, LS, SO, QS, WG, and NQ had higher genetic diversities than other populations (Table 3).

GENETIC DIFFERENTIATION AND GENE FLOW OF POPULATION Groups. The Delta $K$ values peaked at $K=2$ in both the correlated and independent allele frequency models (Table 4; Fig. 1). The membership coefficients of individuals and populations under the two models were almost the same (Fig. 2). A genotype was assigned to the gene pool in which it had the highest membership coefficient. Populations BT, BX, FX, GQ, $\mathrm{HC}, \mathrm{XF}, \mathrm{ZN}$, and NX were mainly distributed west of the Taihang Mountains and were mainly composed of gene pool I (green in Figs. 2 and 3A). Populations CY, QS, SO, SS, SX, and WG were mainly composed of gene pool II (red in Figs. 2 and $3 \mathrm{~A}$ ) and were located east of the Taihang Mountains. Most of the individuals of populations CL, LB, LS, and NQ were located around the Taihang Mountains, roughly being between population representatives of gene pools I and II, and contained mixed gene pools (Fig. 3A). These populations

Table 3. Genetic variation within 18 Pyrus betulaefolia populations in northern China based on 13 SSR loci.

\begin{tabular}{lccccc}
\hline & \multicolumn{5}{c}{ Genetic variation $^{\mathrm{y}}$} \\
\cline { 2 - 6 } Population code $^{\mathrm{z}}$ & $N_{\mathrm{a}}$ & $N_{\mathrm{e}}$ & $H_{\mathrm{o}}$ & $H_{\mathrm{e}}$ & $A_{\mathrm{r}}$ \\
\hline BT & 8.0 & 4.3 & 0.64 & 0.68 & 6.52 \\
BX & 6.2 & 3.8 & 0.63 & 0.67 & 5.57 \\
CL & 5.7 & 3.6 & 0.62 & 0.68 & 5.56 \\
CY & 4.6 & 2.2 & 0.67 & 0.51 & 3.89 \\
FX & 6.8 & 3.8 & 0.65 & 0.68 & 6.07 \\
GQ & 7.0 & 4.4 & 0.71 & 0.71 & 6.23 \\
HC & 6.8 & 4.1 & 0.67 & 0.67 & 5.54 \\
LB & 7.2 & 4.7 & 0.77 & 0.75 & 6.58 \\
LS & 7.6 & 4.6 & 0.71 & 0.74 & 6.92 \\
NQ & 8.2 & 4.3 & 0.62 & 0.71 & 6.42 \\
NX & 8.0 & 4.6 & 0.75 & 0.75 & 6.55 \\
QS & 7.8 & 4.4 & 0.71 & 0.74 & 6.54 \\
SO & 8.0 & 4.5 & 0.74 & 0.76 & 6.74 \\
SS & 6.1 & 3.5 & 0.66 & 0.70 & 5.19 \\
SX & 6.7 & 3.9 & 0.71 & 0.70 & 5.58 \\
WG & 7.2 & 4.0 & 0.67 & 0.71 & 6.16 \\
XF & 7.6 & 4.9 & 0.71 & 0.77 & 7.62 \\
ZN & 7.6 & 4.3 & 0.71 & 0.71 & 6.28 \\
\hline SSR & & & & &
\end{tabular}

$\mathrm{SSR}=$ simple sequence repeat.

${ }^{\mathrm{z}} \mathrm{BT}=$ Baota District, Yan'an City; BX = Binxian County; FX = Fuxian County; GQ = Ganquan County; HC = Huachi County; XF = Xifeng District, Qingyang City; ZN = Zhengning County; NX = Ningxian County; $\mathrm{CL}=$ Changli County; LB = Lingbao County; LS = Lushi County; NQ = Neiqiu County; CY = Chengyang District, Qingdao City; QS = Queshan County; SO = Songxian County; SS = Sishui County; SX = Shexian County; WG = Wugang County. BT, BX, FX, and GQ are in Shaanxi Province. HC, XF, ZN, and NX are in Gansu Province. CL, NQ, and SX are in Hebei Province. LB, LS, QS, SO, and WG are in Henan Province. CY and SS are in Shandong Province. ${ }^{\mathrm{y}} N_{\mathrm{a}}=$ number of different alleles, $N_{\mathrm{e}}=$ number of effective alleles, $H_{\mathrm{o}}=$ observed heterozygosity, $H_{\mathrm{e}}=$ expected heterozygosity, $A_{\mathrm{r}}=$ allelic richness. 
Table 4. Gene pool number simulation in populations of Pyrus betulaefolia in northern China with Delta $K$ values for $K=1-10$ in independent and correlated models.

\begin{tabular}{lcccrccccc}
\hline & \multicolumn{8}{c}{ Delta $K^{\mathrm{y}}$} \\
\cline { 2 - 9 }$K^{\mathrm{z}}$ & 2 & 3 & 4 & \multicolumn{1}{c}{5} & 6 & 7 & 8 & 9 & \multicolumn{1}{c}{10} \\
\hline Correlated & 407.08 & 3.83 & 1.42 & 0.40 & 5.93 & 0.27 & 0.31 & 0.68 & 16.90 \\
Independent & 605.19 & 1.25 & 4.22 & 16.41 & 3.53 & 0.97 & 0.24 & 1.74 & 2.69
\end{tabular}

${ }^{\mathrm{z}} K=$ number of homogeneous gene pools.

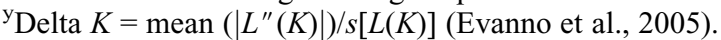

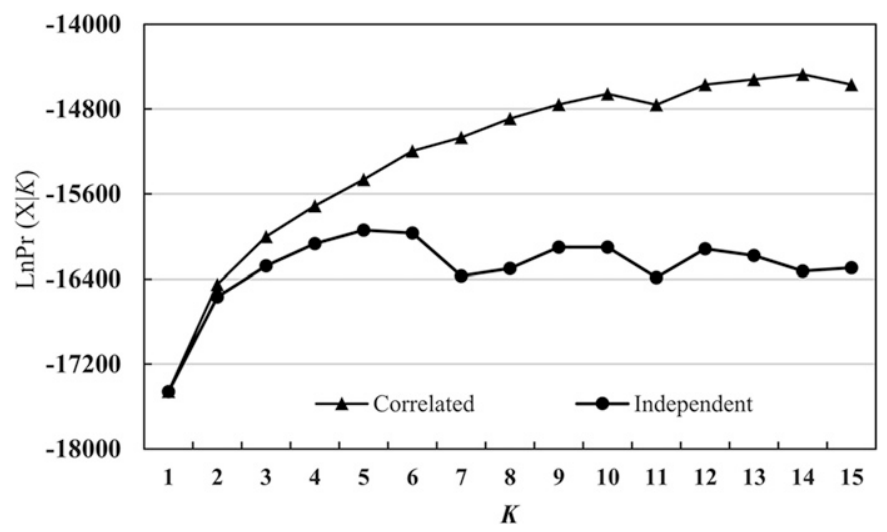

Fig. 1. Clusters number in Pyrus betulaefolia detected using STRUCTURE 2.3.4 (Stanford University, Palo Alto, CA). $\operatorname{Ln} \operatorname{Pr}(X \mid K)$ values were calculated following the method described by Evanno et al. (2005). $K=$ number of homogeneous gene pools; $P(X \mid K)$ is an estimate of the posterior probability of the data for a given $K$ (Pritchard et al., 2000).
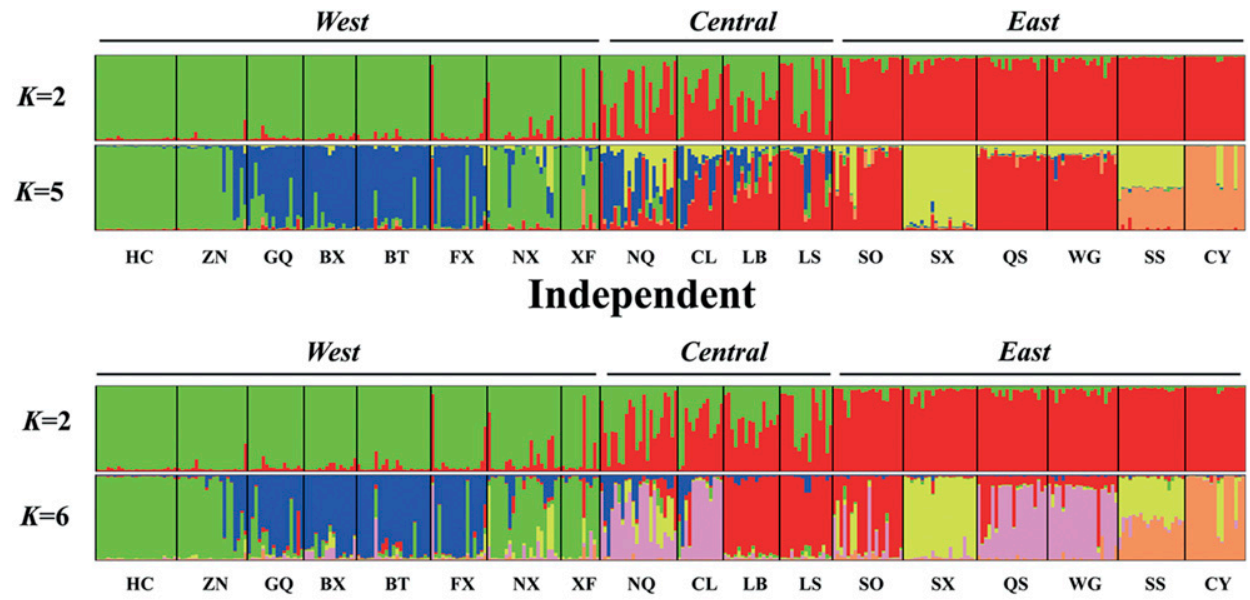

\section{Correlated}

Fig. 2. Population structure of 18 Pyrus betulaefolia populations in northern China revealed by a Bayesian modeling approach. Different populations are split by vertical black lines. Codes below the color bars indicate different populations, and characters on top of the color bars represent the inferred population groups. $\mathrm{BT}=\mathrm{Baota}$ District, Yan'an City; BX = Binxian County; FX = Fuxian County; GQ = Ganquan County; HC = Huachi County; $\mathrm{XF}=$ Xifeng District, Qingyang City; $\mathrm{ZN}=$ Zhengning County; $\mathrm{NX}=$ Ningxian County; $\mathrm{CL}=$ Changli County; LB = Lingbao County; LS = Lushi County; $\mathrm{NQ}=$ Neiqiu County; $C Y=$ Chengyang District, Qingdao City; $\mathrm{QS}=$ Queshan County; $\mathrm{SO}=$ Songxian County; $\mathrm{SS}=$ Sishui County; $\mathrm{SX}=$ Shexian County; $\mathrm{WG}=$ Wugang County. BT, BX, FX, and GQ are in Shaanxi Province. HC, XF, ZN, and NX are in Gansu Province. CL, NQ, and SX are in Hebei Province. LB, LS, QS, SO, and WG are in Henan Province. CY and SS are in Shandong Province.

around the Taihang Mountains were considered the central population group, and the other two were considered east and west population groups, for subsequent analyses.
In the independent model, the second-highest Delta $K$ value was found at $K=5$. Moreover, the value of $\operatorname{LnPr}(X \mid K)$ seemed to plateau at $K=5$ (Fig. 1), which indicates that the model with two gene pools could be further divided with additional resolution provided under the model with $K=5$. Under this model, $P$. betulaefolia individuals were separated into several groups. Gene pool I [cluster in green (Fig. 3B)] was mainly found in populations , XF, NX, and ZN. Gene pool II [cluster in blue (Fig. 3B)] was sampling area and corresponded to gene pool I (green in Fig. 3A) model $K=2$. Gene pool III [cluster in red (Fig. 3B)] was in populations SO, QS, and WG. Gene pool IV [cluster in (Fig. 3B)] was discovered unique to populations SX and SS. gertern part of the sampling area. Fig. 3B) still showed high heterozygosity, which was consistent with the findings with model $K=2$. However, there was no (data not shown).

However, the second-highest value of Delta $K$ appeared at $K=10$, and the third-highest value was observed at $K=6$ in the correlated model (Table 4). The value of $\operatorname{Ln} \operatorname{Pr}(X \mid K)$ seemed to overall plateau between $K=5$ and $K=10$ (Fig. 1), although it did not peak as clearly as was observed in the independent model. As suggested by Pritchard et al. (2000), the smallest value of $K$ that captures most of the structure in the data should be used. With a prior hypothesis that allele frequencies in distinct populations were reasonably different from each other, the independent model works well for many data sets (Pritchard et al., 2000). Consequently, $K=5$ was used as the optimal classification when we described the geographic distribution of genetic composition.

At $K=5$ in the independent model, gene pool I at $K=2$ was subdivided into two portions: subgroup 1, which included populations $\mathrm{HC}, \mathrm{XF}, \mathrm{NX}$, and $\mathrm{ZN}$ and subgroup 2, which included populations GQ, BT, FX, and BX. These two subgroups were separated by the Jing River, which is the largest secondary tributary of the Yellow River. Interestingly, population BX is located on the opposite side as populations GQ, $\mathrm{BT}$, and FX, which indicated a different population formation process than was observed for other populations. Moderate gene pool changes were discovered in populations $\mathrm{SO}, \mathrm{QS}$, and WG compared with that at $K=2$. Populations SX and CY revealed a unique genetic composition at $K=5$; gene pools IV and V represented the overwhelming majority of their gene pools, respectively. 
A

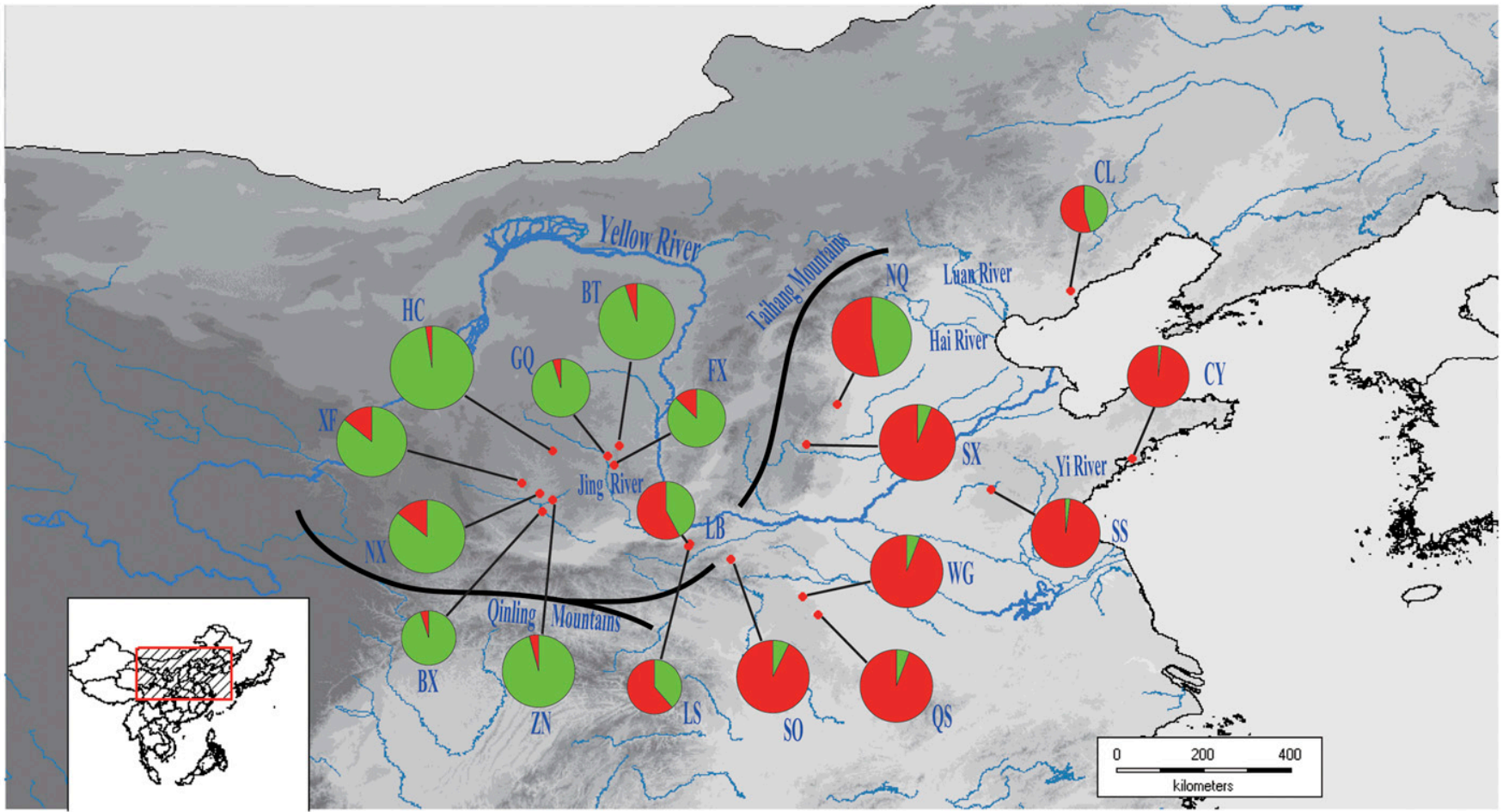

B

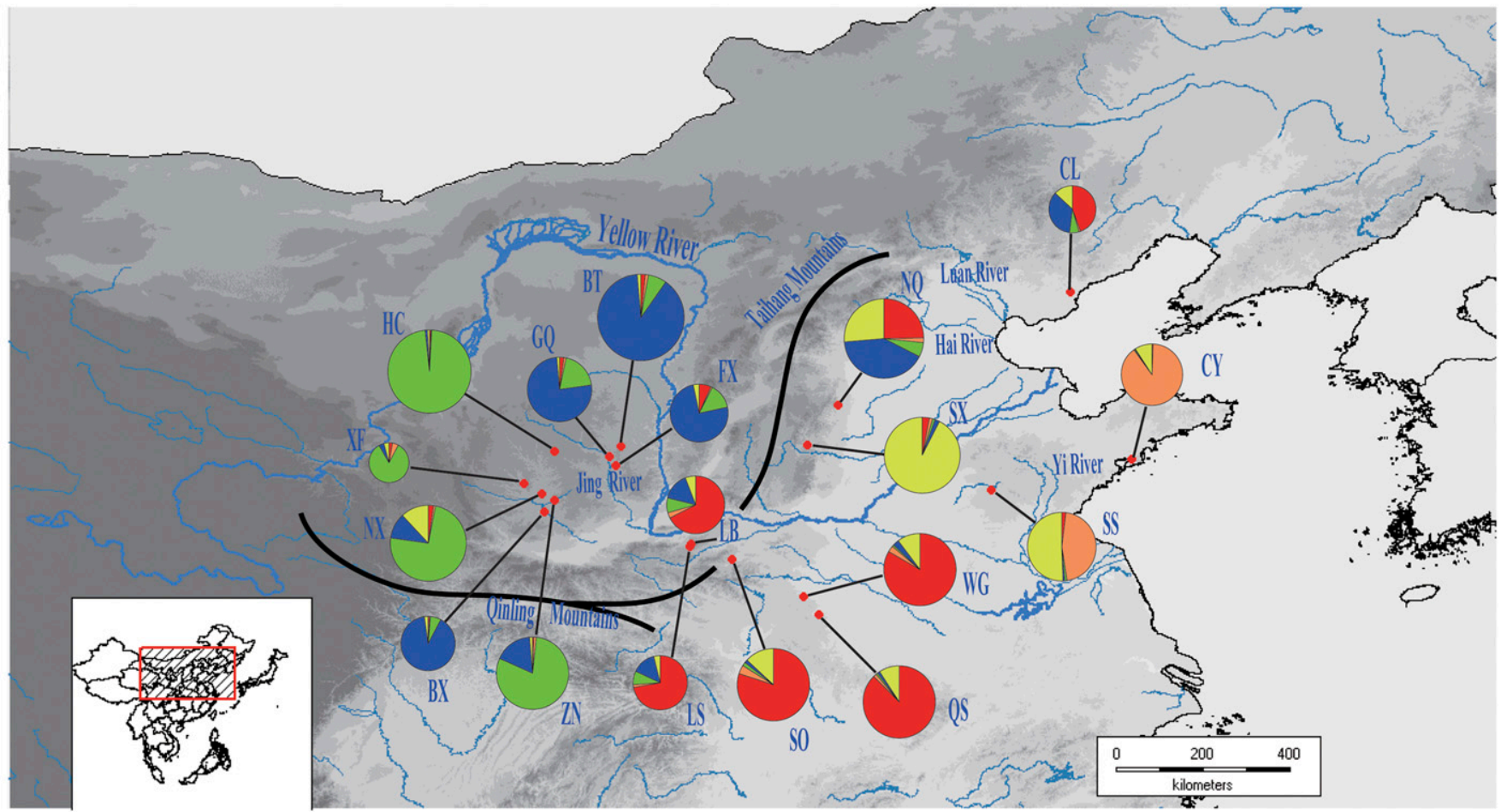

Fig. 3. Geographical location and proportion of gene pools distributed in 18 Pyrus betulaefolia populations in northern China. Solid circle size is correlated with the number of individuals in each population. Black solid lines show the location of the Qinling Mountains and Taihang Mountains. Blue curves represent rivers. A gene pool distribution at $K=2 ; \mathbf{B}$ gene pool distribution at $K=5$. BT = Baota District, Yan' an City; BX = Binxian County; FX = Fuxian County; $\mathrm{GQ}=$ Ganquan County; $\mathrm{HC}=$ Huachi County; $\mathrm{XF}=$ Xifeng District, Qingyang City; ZN = Zhengning County; NX = Ningxian County; $\mathrm{CL}=$ Changli County; LB = Lingbao County; LS = Lushi County; $\mathrm{NQ}=$ Neiqiu County; $C Y=$ Chengyang District, $Q$ ingdao City; $Q S=Q$ Queshan County; $\mathrm{SO}=$ Songxian County; SS = Sishui County; $\mathrm{SX}=$ Shexian County; WG = Wugang County. BT, BX, FX, and GQ are in Shaanxi Province. HC, XF, ZN, and NX are in Gansu Province. CL, NQ, and SX are in Hebei Province. LB, LS, QS, SO, and WG are in Henan Province. CY and SS are in Shandong Province. 


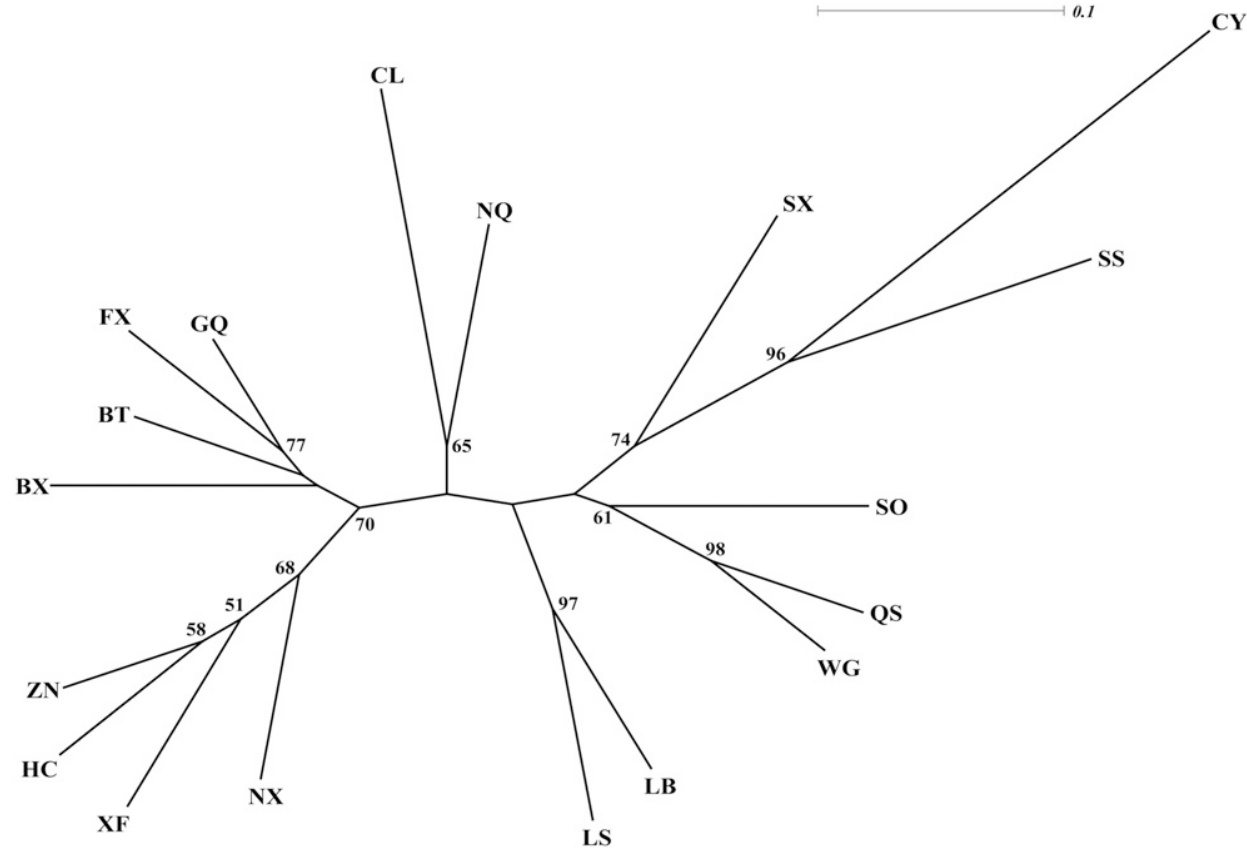

Fig. 4. Neighbor-joining tree of the 18 Pyrus betulaefolia populations based on Nei's genetic distance (Nei et al., 1983). Numbers next to branches indicate bootstrap values based on 1000 replications. BT = Baota District, Yan'an City; BX = Binxian County; FX = Fuxian County; GQ = Ganquan County; HC = Huachi County; XF = Xifeng District, Qingyang City; $Z N=$ Zhengning County; $N X=$ Ningxian County; $C L=$ Changli County; LB $=$ Lingbao County; LS = Lushi County; NQ = Neiqiu County; CY = Chengyang District, Qingdao City; QS = Queshan County; SO = Songxian County; SS = Sishui County; SX = Shexian County; WG = Wugang County. BT, BX, FX, and GQ are in Shaanxi Province. HC, XF, ZN, and NX are in Gansu Province. CL, NQ, and SX are in Hebei Province. LB, LS, QS, SO, and WG are in Henan Province. CY and SS are in Shandong Province.

The NJ tree using Nei's genetic distance (Fig. 4) showed a similar pattern in genetic differentiation of populations to that displayed in STRUCTURE analysis. Both the STRUCTURE analyses and NJ tree revealed three "population groups" (west, central, and east) at $K=2$, which corresponded to the locations of populations and distinct genotypes (Figs. 3 and 4). Mantel test revealed no significant IBD among the $18 P$. betulaefolia populations $(r=0.181, P=0.137)$ and among population groups $(r=-0.861, P=0.169)$. There was also no significant correlation among populations within the east population group ( $r=0.366, P=0.102)$. However, Mantel test revealed marginally significant IBD among populations within the west population group $(r=0.364, P=0.058)$ and significant correlation among populations within the central population group $(r=0.953, P=0.043)$.

Five statistical indexes, including $A_{\mathrm{r}}, H_{\mathrm{o}}, H_{\mathrm{s}}, F_{\text {is }}$, and $F_{\text {st }}$, were compared with reveal whether there were any genetic differences among the three population groups. The west population group showed the highest allelic richness and lowest genetic differentiation among the populations. Although the highest values of $H_{\mathrm{o}}$ and $H_{\mathrm{s}}$ were discovered in the east population group, these indexes were only slightly higher than those of the west and central groups. The central population group had equal allelic richness to that of the east group, but had the only negative $F_{\text {is }}$ value and a significantly $(P<0.01)$ higher $F_{\text {st }}$ value (Table 5 ).

Results obtained using MIGRATE revealed a high level of gene flow among population groups. Of the six pairwise comparisons based on microsatellite STRUCTURE division, the value of $4 N_{\mathrm{m}}$ ranged from $9.96\left(4 N_{\mathrm{mCentral}} \rightarrow\right.$ West $)$ to 47.73 $\left(4 N_{\text {mWest } \rightarrow \text { Central }}\right.$; Table 6$)$. However, asymmetrical gene flow was discovered between the west and central population groups, and between the east and central population groups.

\section{Discussion}

Overall hevel of genetic DIVERSITY OF WILD $P$. BETULAEFOLIA. The results in this study showed a high degree of genetic diversity in $P$. betulaefolia populations. The average number of alleles per locus detected in our study was 7.1, which was higher than the values reported in wild $P$. calleryana (Liu et al., 2012), $P$. calleryana var. dimorphophylla (Kato et al., 2013), and some european pear $(P$. communis) cultivars (Brini et al., 2008; Wünsch and Hormaza, 2007). $H_{\mathrm{o}}$ and $H_{\mathrm{e}}$ values were positively correlated with allele number, and vice versa (Sehic et al., 2012). Heterozygosity refers to possession of different alleles at a given locus, and heterozygosity level could reflect greatly the status of genetic variability (Gregorius and Roberds, 1986; Miller and Tanksley, 1990). The observed heterozygosity of $P$. betulaefolia (0.687) was higher than those of other wild species or cultivated types of Pyrus reported in previous studies (Bao et al., 2007; Bassil and Postman, 2010; Kimura et al., 2002; Liu et al., 2012).

Genetic AND Phylogeographic structure of $\boldsymbol{P}$. BETULAEFOLIA. Our previous study based on cpDNA revealed four $P$. betulaefolia population groups (Zong et al., 2014), whereas results from SSR indicated three population groups. Besides, a positive correlation between genetic divergence and geographic distance among populations was inferred from cpDNA data in previous study (Zong et al., 2014), not from SSR data in this study. Studies performed on Veratrum (Kikuchi et al., 2010, 2013) and Ficus (Bai et al., 2010) have also shown that discordant genetic structure, phylogeography, or both revealed by cpDNA and nuclear variation, which likely resulted from the different mobility of pollen relative to seeds.

Populations SS and SX were clustered together with western populations in our previous cpDNA study (Zong et al., 2014). These two populations were clustered into east group in the current study. The discordance could be ascribed to the

Table 5. Comparison of genetic diversity among different population groups of Pyrus betulaefolia in northern China.

\begin{tabular}{lccccc}
\hline & \multicolumn{5}{c}{ Genetic diversity parameters } \\
\cline { 2 - 6 } Groups & $A_{\mathrm{r}}$ & $H_{\mathrm{o}}$ & $H_{\mathrm{s}}$ & $F_{\text {is }}$ & $F_{\text {st }}$ \\
\hline West & 6.30 & 0.684 & 0.703 & 0.026 & 0.064 \\
Central & 5.96 & 0.686 & 0.675 & -0.017 & 0.157 \\
East & 5.96 & 0.692 & 0.718 & 0.037 & 0.079
\end{tabular}

$\overline{A_{\mathrm{r}}}=$ allelic richness, $H_{\mathrm{o}}=$ observed heterozygosity, $H_{\mathrm{s}}=$ gene diversity, $F_{\text {is }}=$ fixation index, $F_{\text {st }}=$ genetic differentiation among populations. 
Table 6. Estimates of gene flow $\left(4 N_{\mathrm{m}}\right)$ for all pairwise group combinations of Pyrus betulaefolia in northern China.

\begin{tabular}{lcccc}
\hline Groups, $\mathrm{i}$ & $\theta_{\mathrm{i}}^{\mathrm{z}}$ & West $\rightarrow \mathrm{i}$ & Central $\rightarrow \mathrm{i}$ & East $\rightarrow \mathrm{i}$ \\
\hline West & 0.098 & & $\mathbf{9 . 9 6}^{\mathrm{y}}$ & 20.91 \\
& $0.096-0.100$ & & $5.63-14.26$ & $16.13-25.74$ \\
Central & 0.096 & $\mathbf{4 7 . 7 3}^{\mathrm{y}}$ & & $\mathbf{3 8 . 5 0}^{\mathrm{y}}$ \\
& $0.093-0.100$ & $37.07-61.34$ & & $29.63-48.54$ \\
East & 0.098 & 33.77 & $\mathbf{1 0 . 6 0}^{\mathrm{y}}$ & \\
& $0.096-0.100$ & $25.59-40.80$ & $6.40-14.80$ & \\
\hline
\end{tabular}

${ }^{\mathrm{z}}$ The range estimates below each value represent the $95 \%$ confidence interval.

${ }^{\mathrm{y}}$ Numbers in bold indicate that asymmetrical gene flow was found.

dominant position of an ancestral haplotype (H4) in that group (Zong et al., 2014). The same scenario was observed in population NQ because more than $70 \%$ of individuals had the same haplotype (Zong et al., 2014). CpDNA data indicated that SS and SX might be recolonized from population NQ (Zong et al., 2014). However, a distinct gene pool (represented in brown) was found in population SS when $K=5$ in this study (Fig. 2). The genetic composition of population SS was more analogical with population SX than that with population NQ inferred from SSR data. Population SX is geographically close to population NQ. It was dominated by one gene pool (represented in yellow), whereas population NQ showed a mixed gene pool when $K=5$ (Fig. 3B). The different genetic composition between population SX and population NQ may be ascribed to different primitive genetic resources.

Both cpDNA (Zong et al., 2014) and SSR analyses (Figs. 3 and 4) revealed that SS and SX had similar genetic backgrounds. Immigration based on birds and rodents does not seem to explain the similar genetic backgrounds between populations SX and SS because it is such a long distance; populations SX and SS are located in the upstream and downstream areas of the Yellow River, respectively. The large amount of fine-grained loess carried by the river from the Loess Plateau, which is continuously deposited along the bottom of its channel, caused noticeable shifts in watercourse 26 times, of which nine were severe (Tregear, 1965). Population SS with only one cpDNA haplotype H4 (Zong et al., 2014) may have been founded by flood-carrying seed dispersal from population SX dominated by cpDNA haplotype $\mathrm{H} 4$ in the past.

Interestingly, SSR analysis revealed different genetic compositions of the east and west population groups, which are separated by the Taihang Mountains. The Taihang Mountains are oriented northeast to southwest and are a natural boundary between the Loess Plateau and the North China Plain. This result revealed two groups, one from the semihumid North China Plain and another from the semiarid Loess Plateau. Pyrus betulaefolia was distributed in a large area of northern China, and different environmental factors across this vast region could have contributed to the evolution of the two gene pools.

Two different genetic subgroups were detected within the western populations that might be explained by the annual precipitation and direction of the rivers (Figs. 2 and 3 ). Subgroup I (populations HC, XF, NX, and ZN) was from the Wei and Jing River basins, which flow mostly east/west and have annual precipitation that ranges from 470 to $700 \mathrm{~mm}$; the other subgroup (populations GQ, BT, and FX) was from the Yellow River Canyon and surrounding areas, and the Luo and Fen River basins, which flow north/south and have annual precipitation between 300 and $600 \mathrm{~mm}$ (Qu and Wang, 1993). A similar conclusion was found in the study of population structure of sour jujube (Ziziphus acidojujuba) (Zhang et al., 2015). Despite being geographically close to subgroup I populations, population BX had a similar genetic background to subgroup II populations. However, because there was a smaller number of individuals in this population, the genetic structure of this population could be attributed to a genetic bottleneck or founder effect from population NX. The close relationship of these two populations on $\mathrm{NJ}$ tree provided further evidence of this inference (Fig. 4).

The Pyrus stock species is believed to have originated from mountainous regions in western and southwestern China, and spread east and west from there as a result of xerophytism and borealization (Rubtsov, 1944). Nevertheless, the possible place where $P$. betulaefolia initiated was not identified until now. Pyrus betulaefolia was assumed to have evolved during the early or middle Pleistocene (0.6-0.2 million years ago), or possibly even earlier (Zong et al., 2014). Before the Pleistocene, the current range of the Taihang Mountains would have been covered by grassland (Wang and Yan, 2014; Yang et al., 2000), which would be beneficial for rapid colonization by $P$. betulaefolia populations; therefore, we suspect that $P$. betulaefolia were once distributed throughout the Taihang Mountains and the adjacent region. However, with rapid uplift of the Taihang Mountains after the late Pleistocene and climate fluctuation of Quaternary glacial periods, $P$. betulaefolia were fragmented and forced into refuge areas. The Taihang Mountains were reported to be a diversity center for many plants because of their high species richness and endemic plant diversity (Wang and Yan, 2014). Populations in and adjoining the Taihang Mountains probably survived during glacial periods because of the extremely complicated landscape of the Taihang Mountains. Most populations in the western and eastern groups were eradicated, although a few populations in the western group retreated into refuge areas, which was revealed by cpDNA in our previous study (Zong et al., 2014); range expansion and recolonization of $P$. betulaefolia then occurred during interglacial periods.

The central group populations, CL, NQ, LB, and LS, were located around the Taihang Mountains and genetically mixed. Although it was composed of only four populations, the $P$. betulaefolia central population group had comparatively high diversity based on the number of populations within each of the three population groups. Although the cpDNA data analyzed in our previous study (Zong et al., 2014) showed that western populations possessed slightly more haplotypes than eastern populations, those haplotypes were constrained to relatively small areas. Restricted gene flow with IBD was the primary historical process responsible for the observed geographical structure of cpDNA haplotypes within $P$. betulaefolia (Zong et al., 2014). CpDNA is maternally inherited and transfers only via seeds, whereas nuclear DNA is transferred by both seeds and pollen. Seeds are dispersed by birds and rodents (OddouMuratorio et al., 2001), which are not necessarily constrained by natural barriers, but generally spread a short distance. Therefore, cpDNA variation failed to uncover effects of the Taihang Mountains ascribed to gene flow via pollen, which is generally higher than that of seeds. Gene flow revealed by SSR markers showed that almost equal immigration frequency was found between the east and west population groups, but there was asymmetrical gene flow data between the west and central 
population groups, and between the east and central population groups (Table 5). Given the inferences mentioned previously, we speculate that the Taihang Mountains are a putative diversity center of $P$. betulaefolia. If populations remained separated and fragmented at distinct spatial-temporal scales over a long period of time, accumulation of genetic differences between groups in disparate environments would enhance genetic differentiation. However, additional sampling of $P$. betulaefolia surrounding the Taihang Mountains should be performed to produce an in-depth conclusion about its role as a diversity center.

Some populations in east population group also harbored a high level of genetic diversity (represented by heterozygosity). This discordance with the former hypothesis that putative refugial plant populations harbor higher levels of genetic diversity could be attributed to gene introgression caused by hybridization with other Pyrus species. The east population group is mainly distributed in Hebei, Henan, and Shandong Provinces, which are the main production areas of cultivated pear (Pu and Wang, 1963). Hybridization between $P$. betulaefolia and cultivated pear species or types (mainly $P$. pyrifolia and $P$. pyrifolia White Pear Group) might account for some degree of increased polymorphism within $P$. betulaefolia in those areas. The unique gene pools $(K=5$ in Fig. 2) observed in populations SS and CY could have resulted from interspecies hybridization. Similar scenario was also discovered in our previous study using cpDNA (Zong et al., 2014), where a distinct cpDNA haplotype was detected in population CY. Nevertheless, this inference should be treated cautiously because no cultivar samples were included in the current study.

Conservation implications. Continuous urbanization and climate change have led to a decreased number of populations of wild pear species in China over recent decades, and genetic diversity of those wild pears has gradually eroded (Liu et al., 2012; Wuyun et al., 2013, 2015). Measures including ex situ and/or in situ conservation approaches should be performed to preserve the germplasm of wild Pyrus species. Conservation of $P$. betulaefolia should be conducted based on comprehensive evaluation of results inferred from both SSRs and cpDNA. Large populations with high allelic richness and diverse cpDNA haplotypes are considered suitable for protection using an in situ conservation strategy because of potential adaptation to future environmental change (Caballero et al., 2010; Liu et al., 2012). Hence, populations BT, ZN, and QS could be preserved in their original habitats. More research should be conducted on the small populations with mixed gene pools: LB, LS, and NQ. Populations that included more polymorphic alleles and cpDNA haplotypes but contained fewer individuals, such as GQ and XF, are suitable for ex situ conservation. However, ex situ strategies should be used to collect as many individuals of crucial populations as possible to obtain most genetic variation existing within populations, as was also suggested in other studies (Bejaoui et al., 2010; Liu et al., 2012).

Pome seeds with relatively humidity of $25 \%$ could be theoretically stored at $-20{ }^{\circ} \mathrm{C}$ for many years (Volk et al., 2005). It is more economical to preserve genetic diversity in seeds than in field plants when field collections are fully characterized. Volk et al. (2005) proposed a method to store wild apple (Malus sieversii) seeds, which also could be used for the conservation of pear seeds.

\section{Literature Cited}

Ahmed, M., M.A. Anjum, M.Q. Khan, M.J. Ahmed, and S. Pearce. 2010. Evaluation of genetic diversity in Pyrus germplasm native to Azad Jammu and Kashmir (northern Pakistan) revealed by microsatellite markers. Afr. J. Biotechnol. 9:8323-8333.

Asuka, Y., N. Tomaru, N. Nisimura, Y. Tsumura, and S. Yamamoto. 2004. Heterogeneous genetic structure in a Fagus crenata population in an old-growth beech forest revealed by microsatellite markers. Mol. Ecol. 13:1241-1250.

Atangana, A.R., J. Beaulieu, and D.P. Khasa. 2010. Wild genetic diversity preservation in a small-sized first generation breeding population of Allanblackia floribunda (Clusiaceae). Tree Genet. Genomes 6:127-136.

Bai, W.N., W.J. Liao, and D.Y. Zhang. 2010. Nuclear and chloroplast DNA phylogeography reveal two refuge areas with asymmetrical gene flow in a temperate walnut tree from east Asia. New Phytol. 188:892-901.

Bao, L., K. Chen, D. Zhang, Y. Cao, T. Yamamoto, and Y. Teng. 2007. Genetic diversity and similarity of pear (Pyrus L.) cultivars native to east Asia revealed by SSR (simple sequence repeat) markers. Genet. Resources Crop Evol. 54:959-971.

Bassil, N. and J.D. Postman. 2010. Identification of European and Asian pears using EST-SSRs from Pyrus. Genet. Resour. Crop Evol. 57:357-370.

Beerli, P. 2007. Estimation of the population scaled mutation rate from microsatellite data. Genetics 177:1967-1968.

Beerli, P. and J. Felsenstein. 1999. Maximum-likelihood estimation of migration rates and effective population numbers in two populations using a coalescent approach. Genetics 152:763773.

Bejaoui, A., A. Boulila, C. Messaoud, M.N. Rejeb, and M. Boussaid. 2010. Genetic diversity and population structure of Hypericum humifusum L. (Hypericacae) in Tunisia: Implications for conservation. Plant Biosyst. 144:592-601.

Birky, C.W. 1995. Uniparental inheritance of mitochondrial and chloroplast genes: Mechanisms and evolution. Proc. Natl. Acad. Sci. USA 92:11331-11338.

Birky, C.W., P. Fuerst, and T. Maruyama. 1989. Organelle gene diversity under migration, mutation, and drift: Equilibrium expectations, approach to equilibrium, effects of heteroplasmic cells, and comparison to nuclear genes. Genetics 121:613-627.

Boccacci, P., M. Aramini, N. Valentini, L. Bacchetta, M. Rovira, P. Drogoudi, A.P. Silva, A. Solar, F. Calizzano, V. Erdoğan, V. Cristofori, L.F. Ciarmiello, C. Contessa, J.J. Ferreira, F.P. Marra, and R. Botta. 2013. Molecular and morphological diversity of onfarm hazelnut (Corylus avellana L.) landraces from southern Europe and their role in the origin and diffusion of cultivated germplasm. Tree Genet. Genomes 9:1465-1480.

Brini, W., M. Mars, and J.I. Hormaza. 2008. Genetic diversity in local Tunisian pears (Pyrus communis L.) studied with SSR markers. Sci. Hort. 115:337-341.

Caballero, A., S.T. Rodríguez-Ramilo, V. Ávila, and J. Fernández. 2010. Management of genetic diversity of subdivided populations in conservation programmes. Conserv. Genet. 11:409-419.

Challice, J.S. and M.N. Westwood. 1973. Numerical taxonomic studies of the genus Pyrus using both chemical and botanical characters. Bot. J. Linn. Soc. 67:121-148.

China Meteorological Data Service Center. 2012. Statistics of monthly average temperature and precipitation. 28 Aug. 2012. $<$ http://data. cma.cn/en/?r=data/weatherBk>.

Doyle, J. and J. Doyle. 1987. Genomic plant DNA preparation from fresh tissue-CTAB method. Phytochem. Bull. 19:11-15. 
Earl, D.A. and B.M. vonHoldt. 2012. STRUCTURE HARVESTER: A website and program for visualizing STRUCTURE output and implementing the Evanno method. Conserv. Genet. Resour. 4:359-361. Evanno, G., S. Regnaut, and J. Goudet. 2005. Detecting the number of clusters of individuals using the software STRUCTURE: A simulation study. Mol. Ecol. 14:2611-2620.

Fernie, A.R., Y. Tadmor, and D. Zamir. 2006. Natural genetic variation for improving crop quality. Curr. Opin. Plant Biol. 9:196-202.

Ge, X., M.H. Liu, W. Wang, B.A. Schaal, and T. Chiang. 2005. Population structure of wild bananas, Musa balbisiana, in China determined by SSR fingerprinting and cpDNA PCR-RFLP. Mol. Ecol. 14:933-944.

Gianfranceschi, L., N. Seglias, R. Tarchini, M. Komjanc, and C. Gessler. 1998. Simple sequence repeats for the genetic analysis of apple. Theor. Appl. Genet. 96:1069-1076.

Godoy, J.A. and P. Jordano. 2001. Seed dispersal by animals: Exact identification of source trees with endocarp DNA microsatellites. Mol. Ecol. 10:2275-2283.

Goudet, J. 1995. FSTAT (version 1.2): A computer program to calculate F-statistics. J. Hered. 86:485-486.

Gregorius, H.R. and J.H. Roberds. 1986. Measurement of genetical differentiation among subpopulations. Theor. Appl. Genet. 71:826834.

Guilford, P., S. Prakash, J.M. Zhu, E. Rikkerink, S. Gardiner, H. Bassett, and R. Forster. 1997. Microsatellites in Malus $\times$ domestica (apple): Abundance, polymorphism and cultivar identification. Theor. Appl. Genet. 94:249-254.

Heywood, V., A. Casas, B. Ford-Lloyd, S. Kell, and N. Maxted. 2007. Conservation and sustainable use of crop wild relatives. Agric. Ecosyst. Environ. 121:245-255.

Hijmans, R.J., L. Guarino, M. Cruz, and E. Rojas. 2001. Computer tools for spatial analysis of plant genetic resources data: 1. DIVAGIS. Plant Genet. Resour. Newsl. 127:15-19.

Hughes, A.R., B.D. Inouye, M.T.J. Johnson, N. Underwood, and M. Vellend. 2008. Ecological consequences of genetic diversity. Ecol. Lett. 11:609-623.

Huson, D.H. and C. Scornavacca. 2012. Dendroscope 3: An interactive tool for rooted phylogenetic trees and networks. Syst. Biol. 61:10611067.

Jakobsson, M. and N.A. Rosenberg. 2007. CLUMPP: A cluster matching and permutation program for dealing with label switching and multimodality in analysis of population structure. Bioinformatics 23:1801-1806.

Jump, A.S., R. Marchant, and J. Peñuelas. 2009. Environmental change and the option value of genetic diversity. Trends Plant Sci. 14:51-58.

Kato, S., A. Imai, N. Rie, and Y. Mukai. 2013. Population genetic structure in a threatened tree, Pyrus calleryana var. dimorphophylla revealed by chloroplast DNA and nuclear SSR locus polymorphisms. Conserv. Genet. 14:983-996.

Kikuchi, R., P. Jae Hong, H. Takahashi, and M. Maki. 2010. Disjunct distribution of chloroplast DNA haplotypes in the understory perennial Veratrum album ssp. oxysepalum (Melanthiaceae) in Japan as a result of ancient introgression. New Phytol. 188:879-891.

Kikuchi, R., J.H. Pak, H. Takahashi, and M. Maki. 2013. Pattern of population genetic structure revealed by nuclear simple sequence repeat markers in the understory perennial Veratrum album ssp. oxysepalum (Melanthiaceae) with a disjunct pattern of chloroplast DNA haplotypes. Bot. J. Linn. Soc. 108:278-293.

Kimura, T., Y.Z. Shi, M. Shoda, K. Kotobuki, N. Matsuta, T. Hayashi, Y. Ban, and T. Yamamoto. 2002. Identification of Asian pear varieties by SSR analysis. Breed. Sci. 52:115-121.

Klepo, T., R. De la Rosa, Z. Satovic, L. León, and A. Belaj. 2013. Utility of wild germplasm in olive breeding. Sci. Hort. 152:92-101. Langella, O. 2000. Populations 1.2.31. 8 June 2017. $<$ http://bioinformatics. org/ $\sim$ tryphon/populations/>.
Liebhard, R., L. Gianfranceschi, B. Koller, C.D. Ryder, R. Tarchini, E. Van de Weg, and C. Gessler. 2002. Development and characterisation of 140 new microsatellites in apple (Malus $\times$ domestica Borkh.). Mol. Breed. 10:217-241.

Liu, Q., Y. Song, L. Liu, M. Zhang, J. Sun, S. Zhang, and J. Wu. 2015. Genetic diversity and population structure of pear (Pyrus spp.) collections revealed by a set of core genome-wide SSR markers. Tree Genet. Genomes 11:128.

Liu, J., P. Sun, X. Zheng, D. Potter, K. Li, C. Hu, and Y. Teng. 2013. Genetic structure and phylogeography of Pyrus pashia (Rosaceae) in Yunnan Province, China, revealed by chloroplast DNA analyses. Tree Genet. Genomes 9:433-441.

Liu, J., X. Zheng, D. Potter, C. Hu, and Y. Teng. 2012. Genetic diversity and population structure of Pyrus calleryana (Rosaceae) in Zhejiang province, China. Biochem. Syst. Ecol. 45:69-78.

Meilleur, B.A. and T. Hodgkin. 2004. In situ conservation of crop wild relatives: Status and trends. Biodivers. Conserv. 13:663-684.

Miller, J.C. and S.D. Tanksley. 1990. RFLP analysis of phylogenetic relationships and genetic variation in the genus Lycopersicon. Theor. Appl. Genet. 80:437-448.

Miranda, C., J. Urrestarazu, L.G. Santesteban, J.B. Royo, and V. Urbina. 2010. Genetic diversity and structure in a collection of ancient Spanish pear cultivars assessed by microsatellite markers. J. Amer. Soc. Hort. Sci. 135:428-437.

Nei, M., F. Tajima, and Y. Tateno. 1983. Accuracy of estimated phylogenetic trees from molecular data. II. Gene frequency data. J. Mol. Evol. 19:153-170.

Newton, A.C., T.R. Allnutt, A. Gillies, A.J. Lowe, and R.A. Ennos. 1999. Molecular phylogeography, intraspecific variation and the conservation of tree species. Trends Ecol. Evol. 14:140-145.

Oddou-Muratorio, S., R.J. Petit, B. Le Guerroue, D. Guesnet, and B. Demesure. 2001. Pollen-versus seed-mediated gene flow in a scattered forest tree species. Evolution 55:1123-1135.

Okubo, M. and T. Sakuratani. 2000. Effects of sodium chloride on survival and stem elongation of two Asian pear rootstock seedlings. Sci. Hort. 85:85-90.

Peakall, R. and P.E. Smouse. 2006. GENALEX 6: Genetic analysis in Excel. Population genetic software for teaching and research. Mol. Ecol. Notes 6:288-295.

Pritchard, J.K., M. Stephens, and P. Donnelly. 2000. Inference of population structure using multilocus genotype data. Genetics 155:945-959.

$\mathrm{Pu}, \mathrm{F}$. and Y. Wang. 1963. Monograph of fruit trees in China. Vol 3. Pears. Shanghai Sci. Technol. Press, Shanghai, China (in Chinese). $\mathrm{Qu}, \mathrm{Z}$. and Y. Wang. 1993. Monograph of fruit trees in China. Jujube. China For. Press, Beijing, China (in Chinese).

Rana, J.C., R.K. Chahota, V. Sharma, M. Rana, N. Verma, B. Verma, and T.R. Sharma. 2015. Genetic diversity and structure of Pyrus accessions of Indian Himalayan region based on morphological and SSR markers. Tree Genet. Genomes 11:821.

Raymond, M. and F. Rousset. 1995. GENEPOP (Version 1.2): Population genetics software for exact tests and ecumenicism. J. Hered. 86:248-249.

Richards, C.M., G.M. Volk, A.A. Reilley, A.D. Henk, D.R. Lockwood, P.A. Reeves, and P.L. Forsline. 2009. Genetic diversity and population structure in Malus sieversii, a wild progenitor species of domesticated apple. Tree Genet. Genomes 5:339-347.

Robbani, M., K. Banno, K. Yamaguchi, N. Fujisawa, J.Y. Liu, and M. Kakegawa. 2006. Selection of dwarfing pear rootstock clones from Pyrus betulaefolia and P. calleryana seedlings. J. Jpn. Soc. Hort. Sci. 75:1-10.

Rosenberg, N.A. 2004. DISTRUCT: A program for the graphical display of population structure. Mol. Ecol. Notes 4:137-138.

Rousset, F. 2008. genepop'007: A complete re-implementation of the genepop software for Windows and Linux. Mol. Ecol. Resour. 8:103-106.

Rubtsov, G.A. 1944. Geographical distribution of the genus Pyrus and trends and factors in its evolution. Amer. Nat. 78:358-366. 
Schaal, B.A., D.A. Hayworth, K.M. Olsen, J.T. Rauscher, and W.A. Smith. 1998. Phylogeographic studies in plants: Problems and prospects. Mol. Ecol. 7:465-474.

Sehic, J., L. Garkava-Gustavsson, F. Fernández-Fernández, and H. Nybom. 2012. Genetic diversity in a collection of European pear (Pyrus communis) cultivars determined with SSR markers chosen by ECPGR. Sci. Hort. 145:39-45.

Takezaki, N. and M. Nei. 2008. Empirical tests of the reliability of phylogenetic trees constructed with microsatellite DNA. Genetics 178:385-392.

Tamura, F. 2012. Recent advances in research on Japanese pear rootstocks. J. Jpn. Soc. Hort. Sci. 81:1-10.

Tregear, T.R. 1965. A geography of China. Aldine Press, Venice, Italy. van Oosterhout, C., W.F. Hutchinson, D.P. Wills, and P. Shipley. 2004. MICRO-CHECKER: Software for identifying and correcting genotyping errors in microsatellite data. Mol. Ecol. Notes 4:535-538.

Volk, G.M., C.M. Richards, A.A. Reilley, A.D. Henk, P.L. Forsline, and H.S. Aldwinckle. 2005. Ex situ conservation of vegetatively propagated species: Development of a seed-based core collection for Malus sieversii. J. Amer. Soc. Hort. Sci. 130:203-210.

Wang, Y. and G. Yan. 2014. Molecular phylogeography and population genetic structure of $O$. longilobus and O. taihangensis (Opisthopappus) on the Taihang Mountains. PLoS One 9:e104773.

Wolko, Ł., J. Bocianowski, W. Antkowiak, and R. Słomski. 2015. Genetic diversity and population structure of wild pear (Pyrus pyraster (L.) Burgsd.) in Poland. Open Life Sci. 10:19-29.

Wünsch, A. and J.I. Hormaza. 2007. Characterization of variability and genetic similarity of European pear using microsatellite loci developed in apple. Sci. Hort. 113:37-43.

Wuyun, T., H. Amo, J. Xu, T. Ma, C. Uematsu, and H. Katayama. 2015. Population structure of and conservation strategies for wild Pyrus ussuriensis Maxim. in China. PLoS One 10:e133686.

Wuyun, T., T. Ma, C. Uematsu, and H. Katayama. 2013. A phylogenetic network of wild Ussurian pears (Pyrus ussuriensis Maxim.) in China revealed by hypervariable regions of chloroplast DNA. Tree Genet. Genomes 9:167-177.
Yamamoto, T., T. Kimura, Y. Sawamura, T. Manabe, K. Kotobuki, T. Hayashi, Y. Ban, and N. Matsuta. 2002b. Simple sequence repeats for genetic analysis in pear. Euphytica 124:129-137.

Yamamoto, T., T. Kimura, M. Shoda, Y. Ban, T. Hayashi, and N. Matsuta. 2002a. Development of microsatellite markers in the Japanese pear (Pyrus pyrifolia Nakai). Mol. Ecol. Notes 2:14-16.

Yang, X., Q. Xu, H. Zhao, W. Liang, and L. Sunday. 2000. Vegetation changes of the Taihang mountains since the last glacial. Chin. Geogr. Sci. 10:261-269.

Yao, L., X. Zheng, D. Cai, Y. Gao, K. Wang, Y. Cao, and Y. Teng. 2010. Exploitation of Malus EST-SSRs and the utility in evaluation of genetic diversity in Malus and Pyrus. Genet. Resources Crop Evol. 57:841-851.

$\mathrm{Yu}, \mathrm{T} .1979$. Taxonomy of the fruit trees in China. China Agr. Press, Beijing, China (in Chinese).

Zamir, D. 2001. Improving plant breeding with exotic genetic libraries. Nat. Rev. Genet. 2:983-989.

Zhang, C., J. Huang, X. Yin, C. Lian, and X. Li. 2015. Genetic diversity and population structure of sour jujube, Ziziphus acidojujuba. Tree Genet. Genomes 11:1-12.

Zheng, X., D. Cai, D. Potter, J. Postman, J. Liu, and Y. Teng. 2014. Phylogeny and evolutionary histories of Pyrus L. revealed by phylogenetic trees and networks based on data from multiple DNA sequences. Mol. Phylogenet. Evol. 80:54-65.

Zheng, X., C. Hu, D. Spooner, J. Liu, J. Cao, and Y. Teng. 2011. Molecular evolution of $A d h$ and $L E A F Y$ and the phylogenetic utility of their introns in Pyrus (Rosaceae). BMC Evol. Biol. 11:255.

Zong, Y., P. Sun, J. Liu, X. Yue, Q. Niu, and Y. Teng. 2014. Chloroplast DNA-based genetic diversity and phylogeography of Pyrus betulaefolia (Rosaceae) in northern China. Tree Genet. Genomes 10:739-749.

Zong, Y., P. Sun, Q. Niu, and Y. Teng. 2013. Distribution situation and assessment of morphological diversity of wild Pyrus betulaefolia in northern China. Guoshu Xuebao 30:918-923 (in Chinese with English abstract). 